\title{
Giant Lipoma Causing Intestinal Subocclusion: Detachable Snare Loop-Assisted Polypectomy
}

\author{
João Fernandes ${ }^{\mathrm{a}}$ Rui Ramos ${ }^{\mathrm{a}}$ Célia Vicente $^{\mathrm{a}}$ Tobias Teles $^{\mathrm{b}}$ Jorge Canena ${ }^{\mathrm{c}}$ \\ Luís Lopes $^{\mathrm{d}-\mathrm{f}}$ Carlos Casteleiro $^{\mathrm{a}}$ \\ ${ }^{a}$ Gastroenterology Department, Centro Hospitalar Cova da Beira EPE, Covilhã, Portugal; b Surgery Department, \\ Centro Hospitalar Cova da Beira EPE, Covilhã, Portugal; ' Gastroenterology Department, Nova Medical School/ \\ Faculdade de Ciências Médicas de Lisboa, Lisbon, Portugal; d Gastroenterology Department, Hospital Santa Luzia, \\ Viana do Castelo, Portugal; ' ${ }^{2}$ ife and Health Sciences Research Institute (ICVS), School of Medicine, University of \\ Minho, Braga, Portugal; ${ }^{\mathrm{f} I C V S} / 3 B^{\prime}$ s - PT Government Associate Laboratory, Braga/Guimarães, Portugal
}

Keywords

Giant lipoma · Subepithelial lesion · Endoloop •

Polypectomy

\section{Suboclusão intestinal causada por um lipoma gigante: Polipectomia assistida por laço endoscópico}

\section{Palavras Chave}

Lipoma gigante · Lesão subepitelial · Laço endoscópico · Polipectomia

Gastrointestinal lipomas are benign tumors mostly located in the right colon and usually diagnosed during endoscopic procedures [1-4]. Although typically silent, they can cause symptoms such as bleeding, obstruction, invagination, or prolapse. Their tendency to become symptomatic is strongly correlated with their size and location [1-5].

We describe the case of a 78-year-old man reporting recurrent abdominal pain in the last 8 months, during

\section{KARGER}

E-Mail karger@karger.com www.karger.com/pjg
(C) 2018 Sociedade Portuguesa de Gastrenterologia Published by S. Karger AG, Basel

Korger

Open access

This article is licensed under the Creative Commons Attribution NonCommercial-NoDerivatives 4.0 International License (CC BYNC-ND) (http://www.karger.com/Services/OpenAccessLicense). Usage and distribution for commercial purposes as well as any distribution of modified material requires written permission. which he had an episode of intestinal subocclusion. Colonoscopy revealed an $8-\mathrm{cm}$ yellowish pedunculated lesion at the transverse colon occupying the entire lumen (Fig. 1). The yellowish color and presence of a "pillow sign" supported our presumptive lipoma diagnosis.

As the clinical symptoms reported were thought to be caused by the lipoma, it was decided to perform an endoscopic resection (Video) using a single-channel colonoscope. First, we ligated the stalk with 3 detachable snare loops (Endoloop Olympus) in order to prevent bleeding. Then the lipoma was resected en bloc using a polypectomy snare (Fig. 2, 3). There were no adverse events related to the procedure, which lasted $20 \mathrm{~min}$. The patient was discharged on the same day. Histopathological examination showed a submucosal lipoma with an R0 resection. The patient remains asymptomatic 2 years after resection.

Resection of a gastrointestinal lipoma is recommended for symptomatic lesions. Most authors recommend endoscopic excision exclusively in lipomas of up to 20-30 $\mathrm{mm}$, since larger lesions tend to present an unacceptable rate of complications using an endoscopic approach $[2,4$, 5]. However, with the development of new endoscopic 


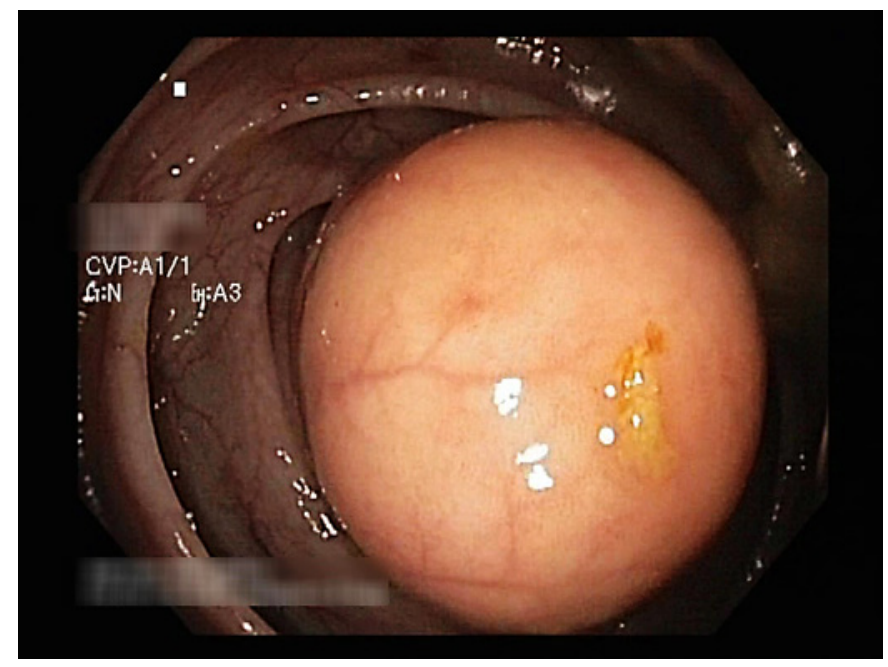

Fig. 1. Endoscopic view of the lipoma occluding the lumen.

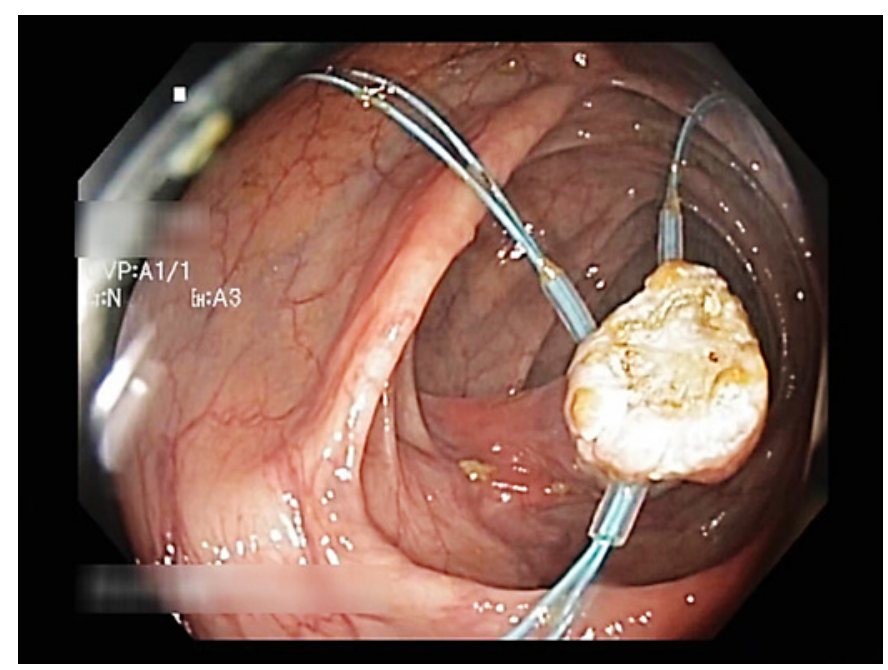

Fig. 2. Remnant stalk.

devices and techniques such as detachable snare loops, we are now able to remove safely these lesions, which were once referred for surgery $[4,5]$.

We highlight this case since, as far as we know after literature search, this is one of the largest lipomas resected by endoscopy, underlining the role of interventional endoscopy in the approach of these lesions.

\section{Statement of Ethics}

This study did not require informed consent nor review/approval by the appropriate ethics committee.

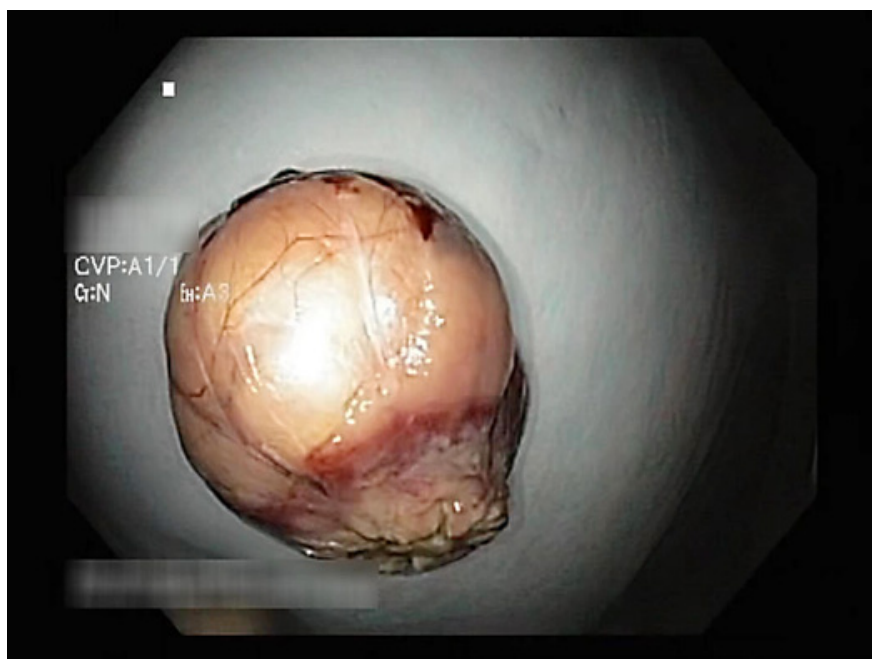

Fig. 3. Resected specimen.

\section{Disclosure Statement}

The authors declare no conflict of interest.

\section{Author Contributions}

J.F., R.R., J.C., and L.L. wrote the manuscript. C.V., T.T., and C.C. were responsible for the revision of its contents.

References

1 Fernandes J, Libânio D, Giestas S, Araújo T, Martinez-Ares D, Certo M, et al: Giant symptomatic rectal lipoma resected by endoscopic submucosal dissection. Endoscopy 2018;50: E63-E64.

2 Panagiotakis GI, Andreou AG, Petrakis IE, Tzardi M, Daskalogiannaki M, Chalkiadakis GE: Laparoscopic resection of a sigmoid colon lipoma in a young female patient: a case report and review of the literature. Oncol Lett 2017;13:1303-1306.

3 Mendes SS, Pinho R, Leite S, Ponte A, Silva J, Rodrigues J, et al: Ligate-and-resect technique for resection of a large pseudo-pedunculated subepithelial lesion in the ascending colon. GE Port J Gastroenterol 2018;25:9698.

4 Lee KJ, Kim GH, Park DY, Shin NR, Lee BE, Ryu DY, et al: Endoscopic resection of gastrointestinal lipomas: a single-center experience. Surg Endosc Other Interv Tech 2014;28:185192.

5 Lorenzo D, Gonzalez JM, Benezech A, Barthet M: Endoscopic resection of giant GI lipoma: a case series. Video GIE 2016;1:43-46.

Fernandes/Ramos/Vicente/Teles/Canena/ Lopes/Casteleiro 